enamel, which is not necessarily " chalky " in character. The rachitic fault, moreover, occurs in certain definite parts of the tooth corresponding to a given period of growth. Caries does not. Amongst the teeth most affected by vitamin shortage in rickets are the lower incisors; yet these teeth are almost immune to enamel caries. Surely if vitamin shortage in early life predisposed the teeth to caries, the lower incisors would be amongst the most susceptible, instead of being amazingly immune.

Mackay (1931), in a report on the association of vitamin $\mathrm{D}$ deficiency and dental caries, showed that there was only slightly greater incidence of caries in a group of rachitic children, 22 per cent. of whom showed hypoplasia of the enamel, than in a control group of normal children in which only 2.5 per cent. showed hypoplasia.

In any case the permeable point in the tooth surface which becomes carious is quite often not a developmental fault at all, and therefore has no relation to avitaminosis. The depth of fissures is a morphological characteristic. Recession of the gums which gives rise to cervical caries is a fault of the parodontal tissues rather than of the tooth, and recurrent caries is a matter of technique. Thus at most vitamin deficiency can only account for one of the four types of caries observed clinically-namely, the interstitial group. Even so, the deficiency would have to extend over a period of about twelve years to affect all the teeth in the way that caries does, and should logically be most intense in the twelfth year, when the wisdom tooth is developing. It seems more likely that the poor calcification of the wisdom tooth is a racial retrogression.

Interstitial and fissure caries appear to be definitely racial and hereditary in character. Tamil and Chinese coolies working together show an extraordinary difference in the incidence of caries. J. W. Field (1929) recorded that 100 Tamils had seven carious teeth while 100 Chinese had 163. Their diet was similar and so was their exposure to sunlight, though the chewing by the Tamils of betel nut with its caustic content might have had an antiseptic effect on the saprophytes.

Up to the Third Dynasty Elliot Smith reports that the Egyptians were free from caries. At this time an invasion of a foreign race occurred, and caries became as prevalent as it is in England to-day.* Even on Tristan da Cunha (Sampson, 1932), where hereditary and not racial factors predominate, of the 156 people examined 26 had an average of eight teeth each, either carious or missing, while 130 were caries-free, and these 26 were largely the " foreign " element of the population, in contradistinction from the 130 , who were chiefly descended from the original stock.

In clinical practice in England it is a matter of common experience that good teeth run in families, so that whatever the factors may be which produce the faults and crevices in which caries develops, they appear to be hereditary.

\section{IMMUNITY TO CARIES}

There are certain cases of this which are significant.

The human subject presents two types of immunity to caries. In one we find. a perfect set of teeth with shallow fissures and faultless enamel. In the other type there are deep fissures and numerous discoloured patches of enamel which show traces of early caries, but the caries has now become completely arrested. The former type appears to have no flaws in which the organisms can lodge, the latter appears to have a mouth which has become inimical to the growth of the saprophytes concerned. If, as he gets older, the man with perfect enamel gets recession of the gums, the exposed necks of the teeth often decay, yet the enamel remains immune, showing definitely that his immunity had been due to absence of faults in the enamel.
On the other hand the presence of faults alone is not sufficient to produce caries, as $M$. Mellanby has shown in her experiments on dogs where faulty enamel was constantly produced, but caries never supervened. Indeed, the dog is immune to caries, and yet it has both deep fissures and permeable lamellae with dead tracts of dentine under them (Fish, 1929). The same observation may be made in the human subject, for as we have seen the hypoplastic teeth of rickets are not especially prone to caries.

There is clearly a factor of susceptibility to an organism or a group of organisms without which caries cannot supervene. The apparently spontaneous arrest of caries is due to acquired immunity and not to a vital reaction in the tooth, since caries often becomes arrested in old broken-down dead roots as well as in deep fissures in vital teeth.

Normally, a change to relative immunity takes place as children grow up. No doubt this is to some extent due to the fact that most permeable faults have by this time been treated, or the tooth has been lost, but it may result in part from a change of diet from milk and sticky carbohydrates to savouries and the use of tea, alcohol, and tobacco. In the same way the use of betel nut may account in some degree for the relative immunity of the Tamil.

\section{CONCLUSION}

Thus all the evidence seems to point to caries being a saprophytic phenomenon occurring in morphological fissures, developmental enamel faults, or in the permeable necks of teeth. In no case can its occurrence be prevented by vital reaction on the part of the formed tooth, though its extension may be delayed. The prevention of decay appears to be possible only by rendering the mouth unsuitable as an environment for the saprophytes concerned, or by breeding a race free from morphological crevices and deyelopmental enamel faults, whose gums will never recede.

\section{REFERENCES}

Boedecker, C. F., and Applebaum, E.: Dental Cosmos, 1930, xxii, 1001

Field, J. W.: British Medical Journal, 1929, i, p. 707.

Fish, E. W.: Dental Record, 1929, xlix, 151.

Idem: British Dental Journal, 1932, liii, 563

Jefferies: British Dental Journal, 1932 (in the press).

Jackay. $\mathrm{H}$. . L ancet 1931, 1230.

Sampson, W. E. A.: British Dental Journal 1932, p. 397.

Sampson, W. E. A.: British Dental Journal 1932, p. 397. "Report on Human Remains at Cairo."

\section{THE AETIOLOGY OF DENTAL CARIES* \\ BY}

\section{MAY MELLANBY}

My only claim to address you is that of one who has devoted many years to physiological and biochemical research, chiefly in relation to teeth and their associated tissues. My approach to the subject of dental disease is therefore somewhat different from that of the clinician, and though we must ultimately arrive at the same destination, we travel by different roads. As none of us can claim to have reached the goal, it is perhaps only natural that we should each tend to emphasize the points elucidated in the course of our own work. No doubt the very fact that Dr. Fish and I have approached the subject from different angles and hold such opposing views prompted the committee to invite us to open this discussion.

* Read in opening a discussion in the Section of Comparative Medicine at the Centenary Meeting of the British Medical Association, London, 1932. 


\section{Animal Research}

My real interest in dental problems arose about 1917, when I noticed that the teeth of my husband's experimental animals varied in character. The teeth of the rickety puppies were irregularly arranged in the jaws and were often rough and pigmented, while the teeth of those free from disease were white, shiny, and in perfect alignment. The failure of all recognized methods of preventing dental disease indicated the need for a different method of approach to the problem, and the opportunity arose, in these puppies, to study the factors modifying the development and resistance of the teeth and related tissues.

A diet was found on which the puppies grew well while their teeth were of poor quality. By making small, and apparently insignificant, additions or alterations to this diet the structure of the teeth and jaws could be completely altered. It was shown that:

1. For the production, in puppies, of well-formed teeth an adequate supply of fat-soluble vitamins, especially vitamin $D$, is essential. (This vitamin can be synthesized in the body by the exposure of the skin to sunlight or to the rays from an ultra-violet lamp.)

2. Cereals antagonize the action of vitamin $\mathrm{D}$ and tend to produce badly formed teeth when this vitamin is deficient.

3. The diet must contain some calcium and phosphorus, the chief components of teeth and bones, but the amount necessary depends largely on the vitamin $\mathrm{D}$ available. When vitamin $D$ is plentiful the quantity and ratio of calcium and phosphorus (above a certain minimum) are of little importance, but when the supply is small, and especially when cereals form a large part of the diet, calcium and phosphorus assume a much greater significance. It is, for instance, possible by raising the calcium in some diets, especially when butter is the source of the vitamin, to convert an insufficiency of vitamin $\mathrm{D}$ into a sufficiency.

4. If a mother is fed during pregnancy and lactation on a diet deficient in vitamin $D$, the offspring show defective calcification of the deciduous teeth; but the defects are less marked than those found in the permanent teeth when the puppies themselves are fed on the same deficient diet, for the mother sacrifices her own stores of essential substances, and may in the process subject herself to harm if the dietetic conditions are severe.

These experiments have recently been repeated, and the main results confirmed and extended by many other investigators.

Vitamin $\mathrm{C}$ has been shown to influence the structure of guinea-pigs' teeth (Zilva and Wells, 1919, and later Höjer and others), but as far as I know it is rare to find defects in man of the type induced in these animals by a deficiency of vitamin $C$. On the other hand, the structural defects commonly found in human teeth are in many respects similar to those found in puppies fed on diets deficient in vitamin $D$, and the fact that human dietaries are often deficient in this vitamin suggests that the defects in the teeth of the experimental dogs and man are of similar origin.

Each vitamin has certain specific functions, and as we learn more about these substances the terminology has to be altered. "The term "vitamin A" now has a narrower meaning than it originally had when it covered the anti-infective growth factor (to which it is now limited) and the anti-rachitic or calcifying factor (now called vitamin D). Both vitamins are fat-soluble, growthpromoting, and affected by heat and oxygenation, and it was for this reason that their actions were at first thought to be due to one entity. In my earlier publications the term " vitamin A" therefore includes both the calcifying and the anti-infective vitamins.
Although caries-like lesions have been produced experimentally in some animals, dogs' teeth appear to be immune to the disease. The normal variations in the minute enamel structure in different species, together with a natural or acquired immunity to the disease, may account, in part at least, for the difficulty of producing caries in some animals as compared with others. For these and other reasons experimental results are not necessarily applicable to the human subject, but they give a lead, and further work on these lines should prove fruitful.

\section{HYPoplasia AND CARIES}

Owing to the difficulty of obtaining a working basis by means of animal experiments, I have adopted an indirect method of testing the liability of human teeth to caries. A large number of shed and extracted teeth (mainly deciduous) were examined, both superficially and histologically, for structure and caries. In the majority the surface enamel was rough, and the minute structure of enamel and dentine was defective, the latter containing interlobular spaces. It was, in fact, clear that the ordinary standard for " hypoplasia " (giving about 3 per cent. of deciduous human teeth as hypoplastic) was not comprehensive enough, and that only comparatively gross defects were ordinarily included in this term. I have therefore used the term " hypoplasia " to denote defective structure of any degree or kind, and the term " gross hypoplasia " for those forms of superficial enamel defect which are commonly recognized. Hypoplasia was found in over 75 per cent. of the human deciduous and in the majority of the permanent teeth examined. The deciduous incisors, largely developed in utero and during lactation, were better calcified than the later-formed molars. For instance, about 60 per cent. of the incisors appeared normal on histological examination, as compared with 1 per cent. of the second molars.

Not only were the great majority of teeth in my collection defective in structure, but there was definite association between structure and caries. The worse the structure, the greater was the liability of the teeth to decay. Only 20 per cent. of the normal teeth were carious, as compared with 94 per cent. of the severely hypoplastic. This close association was found also in groups of Sheffield, Birmingham, and London children. In my experience, there is generally less hypoplasia and caries among the richer children and those living in institutions than among the poorer. Although the association between hypoplasia (as I have described it) and caries has been shown to be a close one, " gross hypoplasia " is not so definitely associated with dental disease.

\section{Rickets}

If structural defects are due to a deficiency of vitamin $D$, and these defects are associated with a liability to caries, it would be expected that the teeth of rickety children would be more liable to disease than those of the average child. The evidence, though not unanimous, generally confirms this expectation. Lawson Dick (1916) found that hypoplasia (gross) was common in the 600 rickety children he examined, and concluded that it was probably the chief factor in premature decay. J. G. Turner states that caries is rather more common in rachitic cases, and $\mathrm{M}^{\prime}$ Gonigle, who examined some thousands of children, comes to a similar conclusion. Again, Wilson and Surie, working among native Indians, conclude that rickets and caries are coexistent. In the Board of Education inquiry (1929) it was found that most of the 1,300 London school children examined showed signs of rickets and caries. Rose and Mackay, on the other hand, compared the 
amount of dental caries in some children, whom they had treated for rickets as babies, with that found in children who at a similar age had suffered from other diseases. They found that although hypoplasia (gross) was confined to the rachitic group, caries was only slightly greater in that group than in the other. The number of rickety children examined (42) was small; it is possible, too, that the treatment they received would delay the carious process. Again, on the basis of recent work it is probable that many of the control children had also passed through a stage of defective calcification, possibly of less severity but longer duration. Some years ago Mr. J. W. Proud, L.D.S., and I examined the teeth of about 200 children diagnosed both at school and in infancy as rachitic, and found a higher percentage of caries in their teeth than in those of the average child.

\section{Possibilities of Dietetic Control}

Having proved to my own satisfaction that the better the structure of the teeth the less the liability to caries, and that structure could be controlled by diet, my next step was to see whether it was possible by variations in diet, especially in the vitamin $D$ and cereal content, to alter the rate of initiation and spread of caries. To this end, from 1921 onwards a series of tests was made in Sheffield, in conjunction with Dr. Lee Pattison, on groups of children, most of whom had badly formed and carious teeth. It was shown that:

1. When the vitamin $D$ content of the diet was increased, and especially when at the same time all cereals were omitted, the initiation and spread of caries were greatly reduced, while the " healing" or arrest of carious areas was very marked.

2. When the vitamin $D$ content of the diet was decreased and extra cereal-for example, oatmeal-was given, the development of dental caries was increased.

An extension of the Sheffield investigations on a larger scale and over a longer period has been made in Birmingham on behalf of the Medical Research Council by Mr. A. Deverall, L.D.S., and Miss M. Reynolds, S.R.N., and the results corroborate those obtained in Sheffield. Boyd and Drain (1928) made some significant observations on a group of children suffering from diabetes. In the course of treatment these children were given a diet devoid of cereals and consisting largely of milk, cream, butter, eggs, meat, cod-liver oil, vegetables, and fruit (that is, a diet rich in vitamin $\mathrm{D}$ and calcium), and the process of dental caries was stopped. Later they fed some non-diabetic children on a similar diet, and again found that active caries was arrested. Bunting also found that of the methods investigated for combating dental caries, dietary measures such as the inclusion of much milk were the most important. $\mathrm{He}$, however, believes that protection is through a change in environment rather than through an increase of resistance of the teeth themselves.

Further evidence bearing on the experimental and clinical observations has rerently been obtained from Tristan da Cunha, the inhabitants of which rarely suffer from dental caries ; their diet includes foodstuffs containing vitamin D and calcium, but is devoid of cereals, and the children are breast-fed for long periods. Other examples of peoples comparatively free from dental disease are the Eskimos and some tribes in tropical lands. Under natural conditions the diet of the former is rich in fat-soluble vitamins and free from cereals. In tropical countries breastfeeding is prolonged in many native tribes, and although the diet consists largely of cereals and the vitamin $D$ content may be low, the skin is exposed to the sun's rays, and the necessary vitamin $D$ is thus synthesized in their bodies. As soon as civilization reaches these peoples the conditions are altered in relation to both diet and clothing. Ultra-violet rays are often prevented from reaching the skin, even of young children. During a visit to Africa some years ago I examined the mouths of hundreds of natives, and found that, although the majority had excellent teeth, the more the tribes conformed to civilized conditions the worse was their dental condition. Heredity has certainly failed here.

In order to test the resistance of erupted teeth, animal experiments were made resulting in the deposition of secondary dentine. A potent calcifying diet during the period of irritation resulted in abundant well-formed secondary dentine; if the calcifying factor was deficient there was no apparent reaction or the secondary dentine formed was imperfect in structure. Here, then, is further evidence that dental reaction can be influenced by nutritional factors.

Contrary to Dr. Fish's experience, I did not often find a "fully calcified barrier" between primary and secondary dentine. This problem, together with that of the character and significance of translucent zones and " dead tracts," will be discussed by others who are much more competent to speak on the subject.

\section{SumMary and Conclusions}

To summarize, fat-soluble vitamins (especially vitamin D) are essential both for calcification of the teeth and for their resistance to disease. The quantity required depends on other factors of diet and environment, including calcium, cereals, and ultra-violet light. The natural foods containing vitamin $D$, with which calcium and vitamin $A$ are often associated, are, unfortunately, comparatively expensive. They include egg yolk, milk, suet, butter, and cheese. (Milk is an excellent food, but I am not yet convinced that there is sufficient evidence that fresh milk is better than the pasteurized product.) Cod-liver oil and some other fish oils are the richest known natural sources of vitamin $\mathrm{D}$; it is present in fat fish (for example, herring, mackerel, and salmon), and also in animal fats (except that of the pig). Vegetable oils as prepared for consumption in England do not usually contain the vitamin. Cereals are cheap, easily stored and transported, and are therefore very common articles of diet ; they are not only devoid of vitamin $\mathrm{D}$, but contain some toxamin, which tends to hinder calcification; the greater the part they play in the dietary the greater must be the intake of vitamin $\mathrm{D}$ and calcium to antagonize their effect.

The clinical work mentioned is only the beginning of this important aspect of nutritional science, for we do not even know the optimum amount of vitamin $D$ required in relation to the other factors of diet and environment.

The literature published during the past decade shows that more attention is being focused on dental caries as a disease resulting from metabolic rather than purely local disturbance. If I have played any part in this new outlook I shall feel justified in having entered the field of dental research.

In conclusion, while I readily admit that the liability of a tooth to decay must depend upon many factors, both intrinsic and extrinsic, I believe that the structure of the tooth is a factor of the highest importance, that this depends in turn upon the diet during the period of growth, and that after eruption its resistance to caries can also be influenced by dietetic conditions. We must, therefore, I believe, concentrate upon the development of more perfect teeth and later also upon increasing their resistance to decay. The practical application of our present knowledge should in time help to diminish the scourge. 